\title{
Smoking habits among the hospital staff of a General Hospital in Northern Greece: a long way for smoke-free hospitals
}

\author{
I. Vagropoulos 1 , T. Tsilchorozidou2, G. Tsinopoulos 1 , Z. Salonikidou1, \\ M. Mouratova ${ }^{1}$, M. Giavropoulou'1, N. Grigoriadis ${ }^{1}$
}

ABSTRACT: Smoking habits among the hospital staff of a General Hospital in Northern Greece: a long way for smoke-free hospitals. I. Vagropoulos, T. Tsilchorozidou, G. Tsinopoulos, Z. Salonikidou, M. Mouratova, M. Giavropoulou, N. Grigoriadis.

Background and Aim. The aim of the study was to evaluate the smoking habits of all staff working in a General Hospital, and to examine whether these habits comply with the introduction of a tobacco law in July 2002, where smoking in enclosed public areas, including hospital buildings, has been forbidden in Greece.

Methods. All hospital staff in Serres General Hospital was asked to complete and return a questionnaire about their smoking habits. The questionnaire was voluntary and anonymous. The survey was conducted from October 2003 to January 2004.

Results. Six hundred and twenty three $(74 \%)$ of the 847 members of staff responded; $310(50 \%)$ were current smokers and $313(50 \%)$ were non-smokers of whom 101 $(32 \%)$ were ex-smokers. The prevalence of current smokers was the highest among nurses $(57 \%)$ and the lowest among doctors $(31 \%)$. Male smokers $(42 \%)$ were outnumbered by female smokers $(54 \%)$ in all age groups up to the age of 60 years $(p<0,01)$, although the reverse is the trend in Greek population ( $47 \%$ and $29 \%$, respectively). The highest rate of smokers was found at the age group of 3140 years $(60 \%)$, while these above sixty years had the smallest (29\%). Seventy percent of current smokers had at least one family member who was current smoker vs $49 \%$ of non-smokers $(\mathbf{p}<\mathbf{0 , 0 0 1})$. The vast majority of smokers $(94 \%)$ continued to smoke in hospital, of whom $62 \%$ smoke more than 5 cigarettes while at work.

Conclusions. The high rate of smokers among the health professionals compared to those in the general population would probably have a negative influence on the development, implementation and inspection of workplace smoking bans in Greece. Increased efforts to promote tobacco education and intervention among doctors and nurses and to establish specialist smoking cessation services throughout the National Health Service should be the standard component of antismoking policy for the law to be effective.

Monaldi Arch Chest Dis 2006; 65: 3, 160-164.

Keywords: Smoking behaviour, tobacco policy, smoke-free hospitals.

1 First Department of Internal Medicine, Serres General Hospital, Serres

2 Division of Endocrinology, Diabetes and Metabolism, AHEPA University Hospital, Thessaloniki, Greece.

Correspondence: Dr Ioannis Vagropoulos; First Department of Internal Medicine, Serres General Hospital; 5 Evzonon Street; 62124 Serres, Greece; e-mail: ivagro@otenet.gr

\section{Introduction}

Cigarette smoking is one of the major causes of death and disease in the United States and Europe. Tobacco use in the United States causes approximately 434,000 deaths each year, including an estimated 3,800 deaths due to lung cancer and 40,000 deaths caused by coronary heart disease among non-smokers exposed to environmental tobacco smoke (ETS) [1,2]. In the European Union it accounts for over half a million deaths each year, while in Europe as a whole for over a million deaths annually [3]. It is estimated that $25 \%$ of all cancer deaths and $15 \%$ of all deaths in the Union could be attributed to smoking. In Greece, $22 \%$ of deaths in men and $3 \%$ in women are attributed to smoking [4], while the prevalence of lung cancer is the highest in the Union at 4,1/100,000 population/year vs 2.5 in the European Region [5].
Although smoking is one of the most important preventable causes of morbidity and mortality worldwide, only the last 15 years efforts have been made by government and private business policies to limit smoking in enclosed public areas, including workplace. While the initial purpose of smoking restrictions in public places was to reduce exposure of non-smokers to environmental tobacco smoke, these restrictions have also been found to contribute to a decrease in the prevalence of smoking and cigarette consumption and to an increase of quitting among smokers [6-8].

In most countries hospitals have addressed the issue of workplace smoking by implementing tobacco control standards, which require banning smoking in hospital buildings [9-12]. Such a tobacco law was introduced in Greece in July 2002, where smoking in enclosed public areas, means of transport and health care services is forbidden. 
However, smoking is still allowed in special designed rooms of these areas, which contrasts with the growing frequency of total bans on smoking in health facilities worldwide. Following the introduction of tobacco law many hospitals in Greece seem to have taken little or no action to reduce smoking by patients and staff in hospital buildings. Hospitals not only being one of the major employers in many communities, but also could have an impact on public regarding tobacco use. We conducted a study concerning smoking behaviour among hospital staff and the implementation of smoking regulations in the workplace.

\section{Materials and methods}

The study was conducted at Serres General Hospital, which is a public hospital with 363 beds serving a population of approximately 210,000 . All full-time employed staff of the hospital was surveyed from October 2003 to January 2004 using an anonymous, self completed questionnaire. The questionnaires were handed to the staff of each department at the place of work with a drop box facility for returning the forms. All the relevant information about the purposes of the study as well as specific instructions how to complete the forms were provided at the beginning of the survey in order to avoid incomplete or duplicate responses. The information requested included sex, age, department at which employed, and whether the responder was a non-smoker or ex-smoker, and if smoker the quantity of cigarettes smoked per day, the quantity of cigarettes smoked while at work if any and the years she/he smokes. They were also asked if they suffer from smoke-related diseases like hypertension, coronary heart disease and respiratory problems. Finally, they were asked to report if any member of their family is current smoker. "Non-smokers" were defined as those who reported having smoked no cigarettes the last 6 months. "Ex-smokers" were defined as those who reported having smoked at least one cigarette per day for a year but smoked no cigarettes the last 6 months. "Smokers" were defined as anyone who habitually smoked cigarettes, regardless of amount.

\section{Statistical analysis}

Data were analysed using the statistical package for social sciences (SPSS Inc, IL, USA). Differences were tested for statistical significance by the $\chi 2$ test for categorical variables. Fisher exact test was applied when the cell sizes were small. A significance level of 0.05 was adopted.

Table 1. - Self-reported smoking habits of hospital staff

\begin{tabular}{|c|c|c|c|c|c|c|c|c|}
\hline \multirow[b]{3}{*}{ Type of staff } & \multirow{2}{*}{\multicolumn{2}{|c|}{ Gender }} & \multirow{2}{*}{\multicolumn{2}{|c|}{ Total No }} & \multicolumn{4}{|c|}{ Smoking habits } \\
\hline & & & & & \multicolumn{2}{|c|}{ Current smokers } & \multicolumn{2}{|c|}{ Non-smokers } \\
\hline & Men & Women & $\mathrm{n}$ & $\%$ & $\mathrm{n}$ & $\%$ & $\mathrm{n}$ & $\%$ \\
\hline Nurses & 23 & 244 & 267 & 43 & 151 & 57 & 116 & 43 \\
\hline Admin/clerical & 32 & 41 & 73 & 12 & 37 & 51 & 36 & 49 \\
\hline Doctors & 73 & 34 & 107 & 17 & 33 & 31 & 74 & 69 \\
\hline Lab staff & 8 & 35 & 43 & 7 & 21 & 49 & 22 & 51 \\
\hline Technical & 27 & 8 & 35 & 6 & 16 & 46 & 19 & 54 \\
\hline Catering & 0 & 16 & 16 & 3 & 6 & 38 & 10 & 62 \\
\hline Domestic/portering & 44 & 38 & 82 & 13 & 46 & 56 & 36 & 44 \\
\hline Total & 207 & 416 & 623 & 100 & 310 & 50 & 313 & 50 \\
\hline
\end{tabular}

Table 2. - Proportions of smokers by age group and gender

\begin{tabular}{|c|c|c|c|c|c|c|c|}
\hline \multirow{3}{*}{$\begin{array}{l}\text { Age group } \\
\text { (years) }\end{array}$} & \multicolumn{4}{|c|}{ Gender } & \multirow{3}{*}{$\begin{array}{c}\text { Total No } \\
\text { of smokers }\end{array}$} & \multirow{3}{*}{$\begin{array}{c}\text { Total No } \\
\text { of responders }\end{array}$} & \multirow[t]{3}{*}{$\%$ smokers } \\
\hline & \multicolumn{2}{|c|}{ Men } & \multicolumn{2}{|c|}{ Women } & & & \\
\hline & $\mathbf{n}$ & $\%$ & n & $\%$ & & & \\
\hline $20-30$ & 12 & 32 & 41 & 50 & 53 & 120 & 44 \\
\hline $31-40$ & 24 & 53 & 113 & 61 & 137 & 229 & 60 \\
\hline $41-50$ & 29 & 48 & 59 & 51 & 88 & 177 & 50 \\
\hline 51-60 & 17 & 35 & 8 & 36 & 25 & 70 & 36 \\
\hline$>60$ & 4 & 33 & 0 & 0 & 4 & 14 & 29 \\
\hline Total No & 86 & 42 & 221 & 54 & $\begin{array}{c}310 \\
(307+3)\end{array}$ & $\begin{array}{c}613 \\
(613+10)\end{array}$ & 50 \\
\hline
\end{tabular}

* Thirteen members of the responders did not complete question on age group (three smokers and 10 non-smokers). 
Table 3. - No of cigarettes/day and No of cigarettes at workplace among smokers

\begin{tabular}{|c|c|c|c|c|c|c|c|c|c|c|c|}
\hline \multicolumn{3}{|c|}{ No of cigarettes/day } & \multicolumn{9}{|c|}{ Smoking behaviour at workplace } \\
\hline \multirow[t]{2}{*}{$\begin{array}{l}\text { Total No } \\
\text { of cig/day }\end{array}$} & \multicolumn{2}{|c|}{$\begin{array}{l}\text { No (and \%) } \\
\text { of smokers }\end{array}$} & \multicolumn{7}{|c|}{ No of cigarettes at workplace } & \multirow{2}{*}{\multicolumn{2}{|c|}{$\begin{array}{c}\text { No and \% } \\
\text { of smokers } \\
\text { at workplace } \\
\text { n } \%\end{array}$}} \\
\hline & $\mathrm{n}$ & $\%$ & $1-5$ & $6-10$ & $11-15$ & $16-20$ & $21-25$ & $26-30$ & $31-40$ & & \\
\hline $1-5$ & 25 & 8 & 15 & & & & & & & 15 & 60 \\
\hline $6-10$ & 50 & 16 & 43 & 4 & 1 & & & & & 48 & 94 \\
\hline $11-15$ & 35 & 11 & 21 & 11 & 3 & & & & & 35 & 100 \\
\hline $16-20$ & 72 & 23 & 17 & 38 & 12 & 1 & & & & 68 & 94 \\
\hline $21-25$ & 46 & 15 & 9 & 25 & 9 & 1 & & & & 44 & 96 \\
\hline $26-30$ & 29 & 9 & 5 & 10 & 9 & 2 & 3 & & & 29 & 100 \\
\hline $31-40$ & 27 & 9 & 1 & 8 & 10 & 6 & 2 & & & 27 & 100 \\
\hline $41-45$ & 8 & 3 & 1 & 1 & 2 & 2 & 2 & & & 8 & 100 \\
\hline $46-50$ & 8 & 3 & 0 & 0 & 3 & 2 & 1 & 1 & 1 & 8 & 100 \\
\hline $51-60$ & 2 & 1 & 0 & 1 & 0 & 1 & & & & 2 & 100 \\
\hline$>61$ & 1 & $<1$ & 0 & 0 & 0 & 1 & & & & 1 & 100 \\
\hline No data & 7 & 2 & 1 & 1 & 0 & 3 & & & 2 & 7 & 2 \\
\hline $\begin{array}{l}\text { Total No } \\
\text { (and \%) }\end{array}$ & 310 & & 113 & 99 & 49 & 19 & 8 & 1 & 3 & 292 & \\
\hline of smokers & & 100 & $(36 \%)$ & $(32 \%)$ & $(16 \%)$ & $(6 \%)$ & $(3 \%)$ & $(<1 \%)$ & $(1 \%)$ & & 94 \\
\hline
\end{tabular}

* Seven members did not complete question on No of cigarettes/day while they did complete question on No of cigarettes at workplace.

\section{Results}

A total of 847 staff employed at Serres General Hospital was identified, of whom 623 (74\%) returned a complete, legible survey. Of these 416 $(68 \%)$ were female hospital staff and 207 (33\%) were male staff. Data from 20 incomplete or illegible surveys were discarded.

Of the 623 responders, $310(50 \%)$ were current smokers and $313(50 \%)$ were non-smokers of whom $101(32 \%)$ were ex-smokers. The prevalence of current smokers was the highest among nurses (57\%), domestic and portering staff (56\%), and the lowest among doctors (31\%) (table 1).

Male smokers (42\%) were outnumbered by female smokers $(54 \%)$ in all age groups up to the age of 60 years $(p<0,01)$, although the reverse is the current trend in Greek population. The highest rate of smokers was found at the age group of 31-40 years $(60 \%)$, while those above sixty years had the smallest (29\%) (table 2).

The vast majority of smokers (94\%) continued to smoke in hospital (in designed areas), of whom $62 \%$ smoke more than 5 cigarettes while at work (table 3). Of the 310 smokers, 33 (11\%) had managed to quit smoking in the past but relapsed, 34 (11\%) reported cigarette smoking-related diseases vs $12 \%$ of non-smokers and $216(70 \%)$ had at least one family member who was current smoker vs $49 \%$ of non-smokers $(p<0,001)$.

\section{Discussion}

The findings in this survey document the high rate of smokers among the hospital staff including health professionals. It is a matter of real concern that, despite the overwhelming evidence that smoking is a major cause of death and illness, up to half of the work force in the hospital are current smokers. The prevalence of current smokers was the highest among nurses (57\%), domestic and portering staff (56\%), administrative and clerk staff $(51 \%)$, and the lowest among doctors $(31 \%)$. Although the trend is the same in surveys of smoking habits in hospitals in the United States and Europe, with the higher prevalence of smoking in nursing and domestic/portering staff and the lowest in doctors [10,13-15], the proportion of smokers among the different types of staff are much higher in our study. Interestingly, the total percentage of smokers of hospital staff in our survey is higher not only compared to those found in studies conducted abroad, but also compared to $34,4 \%$ of the general population in Northern Greece [16] and to $37,6 \%$ of Greek population as a whole [17], making it appear paradox that the hospital workforce is substantially different from the population at large.

We also found a higher proportion of smokers among women than men ( $54 \%$ vs $42 \%$ ) in the hospital staff in all age groups up to the age of 60 years $(p<0,01)$. This difference between the sexes in smoking rates is the reverse not only from that found in surveys conducted in Northern Greece in 2003 (22\% vs 48\%) [16] and in Greek population at large in $2000(29 \%$ vs $47 \%)$ [17], but also in the European Union $(21 \%$ vs $33 \%)$ [18, 19], where the prevalence of smoking is higher in men than women. As table 1 shows, the vast majority of hospital staff consisted of nurses of whom $91 \%$ are women. While gender differences could partially 
explain the smoking differences between different working groups, various factors such as inadequate information about health effects of smoking, peer influences, high level of stress, and educational factors could be implicated as possible explanations for high smoking rates among nursing staff. Although tobacco consumption by women may be declining in some European countries, in our survey the higher proportion of smokers among women than men might be a sign that the proportion of women who smoke is increasing in our country. Therefore, according to a standard model for the dissemination of smoking behaviour based on observations of the development up till now, Greece has passed from stage 1, where smoking rates increase first among men, later among women to stage 2 , where smoking rates still rise among females but decrease among males [20]. Smoking-related deaths are now common among males and start to appear among females. According to this model, in stage 3 smoking rates decrease in both sexes, while smoking-related deaths increase in both sexes and, in stage 4 smoking rates continue to decrease in both sexes and in males smoking-related deaths start to decline, while they continue to increase in females. While many countries in Europe have reached stage 4 [21], Greece is probably still in stage 2, which means that sooner or later Greece has to face up to the public health costs of smoking-related diseases.

It is encouraging to note that doctors had the lowest smoking rate among hospital staff in our study, as it is the case in previous studies conducted at various hospitals in United States $[10[(<5 \%)$ and Europe (12\%) [13, 14]. Although this was still appreciable at $31 \%$ in our survey, it seems to be lower than those found in recent survey in Northern Greece where the prevalence of smoking among doctors working at the National Health System was extremely high at $45 \%$ [16]. Furthermore, in a study conducted in Italy, a country also of the Mediterranean region, 39\% of doctors were smokers vs $44 \%$ of the working staff of the same hospital [22]. In our study, prevalence of smoking among doctors remains lower compared to those found among hospital staff $(\mathrm{p}<0.001)$ or in the general population. While physicians appear to have a better appreciation of the health hazards of smoking and education, the differences between different working staff may be well explain by the higher socioeconomic status which is known to be inversely related to the likelihood of smoking [2325]. However, unlike medical students in the United States where smoking rate has steadily declined at $3.3 \%$ by 2000 [26], smoking rate is 3 to 10 times higher in surveys of medical students from Europe, and reaches $41 \%$ in Greece $[16,27,28]$.

This study also identified a group of smokers $(11 \%)$ who tried to give up smoking in the past, but unsuccessfully. On the other hand $32 \%$ of nonsmokers were ex-smokers. Encouragement and support need to be provided to this motivated group by a smoking cessation counsellor so that they will not relapse and stay for life smoke-free.
Such a service within the hospital may be worthwhile.

Our current hospital policy reflects a concern about the social aspects of smoking and the dangers of passive smoking, as $94 \%$ of the smokers still smoke in hospital building vs $6 \%$ who does not. This happens in spite of the introduction of tobacco law in July 2002, where smoking in hospital buildings has been forbidden in Greece, and the practical knowledge that smoke-free workplace policies effectively reduce expose of non-smokers to ETS and increase the likelihood that smokers in these settings smoke fewer cigarettes or quit $[7,8$, $29,30]$. One could question if the current hospital policy that tolerates smoking results from the attitudes and practices of the working staff, which shows a lack of concern for being an example to the public. It is of high importance that hospitals make a clear statement on public smoking and comply with the tobacco control standards, which required banning smoking in hospital buildings. However, the fact that smoking is still allowed in special designed rooms of public areas, including hospital buildings, contrasts with the growing frequency of total bans on smoking in health facilities worldwide. It seems inevitable that sooner or later we will face up to the public health costs of smoking and enact stricter reforms. Critical success factors include building consensus among all staff whose support is vital, especially among health professionals, in order to have the potential to be credible advisors to patients and the public regarding smoking cessation. Hospital administrations and all other staff may contribute in parallel with dedicated smoking cessation services that need to be established throughout the National Health Services [31-34].

Results from this study must be interpreted in light of the limitation of a self-reported survey design, which might be subject to recall and non-response bias and reporting errors. However, self-report generally has been found to be accurate in population-based-surveys among adults. Also, due to our attempt to maintain anonymity, the possibility of some degree of duplication of surveys cannot be excluded. However, as far as we can check by gender it does not seem that is affected by possible selfselection as the proportion of males and females in the entire hospital staff is $29,4 \%$ and $70,6 \%$ respectively, which is comparable with those of the responders (33\% and $67 \%$ respectively).

The high rate of smokers among the hospital staff in our survey compared to those in the general population would probably have a negative influence on the development, implementation and inspection of workplace smoking bans in Greece. Increased efforts to promote tobacco education and intervention among doctors and nurses and to establish specialist smoking cessation services throughout the National Health Service should be the standard component of antismoking policy for the law to be effective. The introduction of total bans on smoking in health care facilities could considerably strengthen controls in these areas and create a smoke-free environment. 
Acknowledgements: We would like to thank all staff at Serres General Hospital for their cooperation in this survey. We would also thank the Personnel Department for providing formation of all staff members in the hospital.

\section{References}

1. US Centers for Disease Control and Prevention. Cigarette smoking-attributable mortality and years of potential life lost-United States, 1990. MMWR 1993; 42: 645-9.

2. Wells AJ. Passive smoking as a cause of heart disease. J Am Coll Cardiol 1994; 24: 546-54.

3. World Health Organization: Tobacco or Health: First Global Status Report. Geneva, WHO, Tobacco or Health Programme, 1997.

4. Peto R, Lopez AD, Boreham J, Thun M. Mortality from smoking in developed countries 1950-2000, $2^{\text {nd }}$ ed. Oxford, Oxford University Press, 2003.

5. Cancer in the European Union in 1990 EUCAN 90 Version 1.1, Copyright IARC 1996, Lyon, International Agency for Research on Cancer, 1997.

6. CDC. Prevalence of current cigarette smoking among adults and changes in prevalence of current and some day smoking - United States, 1996-2001. MMWR 2003; 52: 303-7.

7. CDC. State-specific prevalence of current cigarette smoking among adults and the proportion of adults who work in a smoke-free environment - United States, 1999. MMWR 2000; 49 (43).

8. Fichtenberg CM, Glantz SA. Effect of smoke-free workplaces on smoking behaviour: systematic review. BMJ 2002; 325: 188-91.

9. US Joint Commission on Accreditation of Healthcare Organizations. Accreditation manual for Hospitals. Oakbrook Terrace, Illinois: Joint Commission on Accreditation of Healthcare Organizations, 1992.

10. Longo DR, Feldman M, Kruse RL, Brownson RC, Petroski GF, Hewett JE. Implementing smoking bans in American hospitals: results of a national survey. Tobacco Control 1998; 7: 47-55.

11. McKee M, Gilmore A, Novotny TE. Smoking free hospitals: an achievable objective bringing benefits for patients and staff. BMJ 2003; 326: 941-2.

12. Mc Robbie H. Smoke free hospitals: rising to the challenge. BMJ 2003; 327: 811-2.

13. Hussain SF, Tjeder-Burton S, Campbell IA, Davies PD. Attitudes to smoking and smoking habits among hospital staff. Thorax 1993; 48: 174-5.

14. Davies PD, Rajan K. Attitudes to smoking and smoking habit among the staff of a hospital. Thorax 1989; 44: 378-81.

15. Senior SL. Study of smoking habits in hospital and attitudes of medical staff towards smoking. CMAJ 1982; 126: 131-3.

16. Sichletidis L, Chloros D, Tsitsios I, Stergiou V, Kaiafa $\mathrm{O}$, Kaouri S et al. The prevalence of smoking in Northern Greece. Hell Iatr 2003; 69: 296-302.
17. Kokkevi A, Loukadakis M, Plagianakou S, Politikou K, Stefanis C. Eur Addict Res 2000; 6: 42-9.

18. Fifth W.H.O. Seminar for a tobacco-free Europe Sports and Arts tobacco-free. Warsaw Poland 26-28 October 1995. EURICR ALTD 9401 MTO2. Greece 1994.

19. World Health Organization. Tobacco Free Initiative Data 2001.

20. Ramström LM. Prevalence and other dimensions of smoking in the world in: Bolliger CT, Fagerström KO (eds): The tobacco epidemic Prog Respir Res. Basel, Karger 1997, 28: 64-77.

21. Peto R, Lopez AD, Boreham J, Thun M, Heath CJr. Mortality from smoking in developed countries 19502000. Oxford, Oxford University Press, 1994.

22. Nardini S, Bertoletti R, Rastelli V, Ravelli L, Donner $\mathrm{CF}$. Personal smoking habit and attitude towards smoking among the health staff of a general hospital. Monaldi Arch Chest Dis 1998, 53; 74-8.

23. Townsend J, Roderick P, Cooper J. Cigarette smoking by socioeconomic group, sex, and age: effect of price, income, and health publicity. BMJ 1994; 309: 923-7.

24. Pekkanen J, Tuomilehto J, Uutela A, Vartiainen E, Nissinen A. BMJ 1995; 311: 589-93.

25. CDC. Cigarette smoking among adults - United States, 2002. MMWR 53: 427-31, 2004.

26. Patkar AA, Hill K, Batra V, Vergare MJ, Leone FT. A comparison of smoking habits among medical and nursing students. Chest 2003; 124: 1415-20.

27. Avlonitou I, Samartzis L, Rigopoulou A, Frageskaki F, Behralis P. Evaluation of smoking habits of Medical School of Athens. Pneumon 2003, 16: 306-13.

28. Mammas I, Bertsias G K, Linardakis M, Tzanakis N E, Labadarios D M, Kafatos A G. Cigarette smoking, alcohol consumption, and serum lipid profile among medical students in Greece. Eur J Public Health 2003 13: 278-82.

29. Alcouffe J, Fau-Prudhomot P, Manillier P, Lidove E, Monteleon PY. Smoking among workers from small companies in the Paris area 10 years after the French tobacco law. Tobacco control 2003; 12: 239-40.

30. Trotter L, Wakefield M, Borland R. Socially cued smoking in bars, nightclubs, and gaming venues: a case for introducing smoke-free policies. Tobacco Control 2002; 11: 300-4.

31. Hollis JF, Lichtenstein E, Vogt TM, Stevens VJ, Biglan A. Nurse-assisted counselling for smokers in primary care. Ann Int Med 1993; 118: 521-5.

32. West R. Helping patients in hospital to quit smoking: dedicated counselling services are effective-others are not. $B M J$ 2002; 324: 64

33. Hajek P, Taylor TZ, Mills P. Brief intervention during hospital admission to help patients to give up smoking after myocardial infarction and bypass surgery: randomised controlled trial. BMJ 2002; 324: 1-6.

34. Joseph AM, Knapp JM, Nichol KL Pirie PL. Determinants of compliance with a national smoke-free hospital standard. JAMA 1995; 274: 491-6. 